\title{
Comparison of effects of a self management booklet and audiocassette for patients with asthma
}

\author{
Douglas Jenkinson, Jan Davison, Sue Jones, Patricia Hawtin
}

\begin{abstract}
The effects on self management of asthma of a specially prepared book and audiocassette tape with similar contents were observed in a controlled study of 177 patients with asthma in general practice. After a run in period of six months patients were randomly given the book, the tape, both the book and tape, or neither. Patients' knowledge of the use of drugs, perceptions of their disability, skill in using an inhaler, consumption of drugs, consultations with their general practitioners, morbidity (from patients' entries on diary cards), and use of the educational material were measured. Knowledge about the use of drugs was significantly increased in the groups who received the material after three months and persisted after 12 months. Patients who had been given the tape or the book and tape increased their scores of knowledge of drugs more than patients given the book alone. Patients in all groups given the material considered that their disability was reduced. There were no other significant changes. Patients given both the book and the tape preferred the book.

Patients with asthma can obtain useful information from such material. The paradoxical result whereby patients learnt more from the tape but preferred the book suggests that a distinction can be made between information that patients need, which may be acquired better from an audiocassette, and information that they want, which may be acquired better from a book.
\end{abstract}

\section{Introduction}

The proper management of asthma often requires that a doctor spends time on tailoring drug treatment, monitoring patients, and teaching self management. More effective methods of educating patients are needed to help reduce morbidity and mortality from the disease. Some studies on selected groups of patients with asthma in North America have improved self management skills and reduced morbidity, particularly with behavioural techniques. ${ }^{1.3}$ Programmes in the United Kingdom to assess plans of management and improve knowledge of asthma in patients in general practices have shown small benefits and have been time consuming. ${ }^{+}$

Written instructions about drug treatment improve compliance," but few doctors provide them. Probably rather more doctors give their patients leaflets or booklets, but evaluation of such material is unusual, although a patient information booklet on management of minor illnesses reduced consultations and was used as a reference manual. ' Audiocassette players are now commonplace, and educational medical tapes are being made. The telephone is also being used for patient education: at least two national organisations provide taped information for the general public on a wide variety of medical topics. We thought it worth while to prepare and compare educational material emphasising self management in both booklet and audiocassette form for patients with asthma; this material did not need any explanation from doctors. We compared the effects of the booklet and tape.

\section{Patients and methods}

THE EDUCATIONAL MATERIAL

The material was prepared in book form by a medical journalist (Jeremy Laurance) and one of us (DJ). The book was 7000 words long, was printed professionally, and consisted of 27 glossy pages of A4 size. The text was broken with amusing illustrations. Nine pages explained the nature and causes of asthma and ordinary preventive measures. Twelve pages explained the types and uses of drugs, how to get the best from them, and the best ways of coping with common problems of asthma. The last section, on what to do when things go wrong, covered 18 possible problems. There was a glossary, and a table identified and classified all commonly used drugs. The language and style were simple, and emphasis was placed on explaining the actions as well as the advantages and disadvantages of various forms of drugs. The booklet was written so it could be used for reference: each section was made as self contained as possible, and there was considerable repetition among sections. The section on what to do when things go wrong was intended specifically to be used for reference and gave precise, practical instructions.

The contents of the audiocassette kept as closely as possible to the same format. Both sides of the tape were used, each lasting about 17 minutes. Side one, spoken by a male "doctor," covered the nature and causes of asthma and the actions of drugs and corresponded to the main part of the book. Side two, the equivalent of the section on what to do when things go wrong in the book, took the form of a conversation between a doctor answering questions about problems asked by a female adult patient. A statement on the tape suggested that it might have to be played several times and could also be used for reference. A separate card with the table of drugs as given in the book was provided with each cassette.

\section{SELECTION OF PATIENTS AND ASSESSMENT}

Asthmatic patients, selected from eight practices in the area that had volunteered to participate, were identified from disease registers that already existed or were constructed for the study. All patients aged 3-49 whose asthma had been diagnosed at least one year previously and who were considered from the medical records to have wheezing on at least 20 days each year were invited to take part in a study of problems caused by asthma. Those who agreed were studied for 18 months. All patients kept diary cards to record weekly scores of morbidity; they noted full and half days lost
Jenkinson, Department of General Practice, Queen's Medical Centre,

Nottingham NG7 2UH 
from work or school; social, domestic, and sporting events disrupted by asthma; and visits to the doctor for asthma, for problems not related to asthma, and for prescriptions for drugs for asthma. The cards were returned monthly. After six months patients in each practice were randomly allocated to one of four study groups and sent the book, the tape, both the book and tape, or neither. No explanation of the purpose of the materials was given; a note simply expressed the hope that the patient would find the material useful. Patients with no cassette player were lent a simple machine.

Questionnaires on patients' knowledge of the use of bronchodilators and prophylactic drugs (if applicable) and their perceived disability from asthma were administered four times. The first was given at the start of the study, the second six months later (immediately before the educational material was provided), the third three months later, and the fourth after a further nine months (one year after the educational material was issued). Parents answered for young children. An interviewer was present (for guidance only) for the first questionnaire, when data were also collected on medical history and current use of drugs. She was also present for the final (fourth) questionnaire, which included questions about the use of the material. The second and third questionnaires were sent by post. Inhaler technique was checked at the interviews whenever possible. Medical records were searched to establish the number and purpose of consultations and consumption of drugs for asthma during the study period.

\section{SCORING AND DATA ANALYSIS}

Scoring systems were devised for each measurement. On the questionnaire on knowledge of the use of drugs patients answered only questions that were relevant to the drugs they were taking. Questions were weighted according to importance, points were deducted for wrong answers, and the total score was expressed as a percentage of the maximum possible. The questionnaire on perceived degree of disability asked patients to rate their work or school, sport, holidays, home life, and other social life on a five point scale from "never affected" to "very often affected" by asthma. They

TABLE I-Mean change in scores for knowledge of drugs during study

\begin{tabular}{lccccc}
\hline Study group & $\begin{array}{c}\text { No in } \\
\text { group }\end{array}$ & $\begin{array}{c}\text { Mean score at } \\
\text { start of study }\end{array}$ & $\begin{array}{c}\text { Mean score at } \\
\text { end of run in } \\
\text { period }\end{array}$ & $\begin{array}{c}\text { Mean change } \\
\text { three months } \\
\text { after intervention }\end{array}$ & $\begin{array}{c}\text { Mean change } \\
\text { one year after } \\
\text { intervention }\end{array}$ \\
\hline $\begin{array}{l}\text { Control } \\
\text { Book }\end{array}$ & 40 & 52 & 57 & 0 & -5 \\
Tape & 44 & 57 & 62 & $4 \dagger$ & 4 \\
Book and tape & 41 & 51 & 57 & $17 \dagger$ & $11 \neq$ \\
\hline
\end{tabular}

^Not all patients could be assessed.

tCompared with end of run in period: $p=0.002$ (analysis of variance)

†Compared with control group: $p=0 \cdot 007$ (analysis of variance).

were also asked whether asthma made them feel different from other people and whether they avoided telling people they had asthma. A simple total was obtained. Skill in the use of an inhaler was scored on a three point scale on two aspects for powder inhalers and three for aerosols. Morbidity was calculated from the diary cards by counting the number of days affected in the defined categories in three periods of six months: comparisons were made between the first six months (the run in period) and the next two periods, the second being the same calendar months as the run in period. Information on the frequency and type of use of the book and cassette was obtained by open and closed questions at the final interview.

The coded data were transferred to a computer and analysed with the statistical package for the social sciences. A two way analysis of variance was used to analyse the main effects of the book and the tape on changes in knowledge of drug use and the extent to which the book and tape interacted. Information from the diary cards on the number of days that various activities were affected by asthma was analysed with the Kruskal-Wallis one way analysis of variance. $\chi^{2}$ Tests were used for categorical data.

\section{Results}

From the disease registers kept by the practices we identified 306 patients, 260 of whom agreed to take part in the study. Ten patients were found to be ineligible because they did not have asthma and three because they had other chest diseases. Eleven patients were excluded because they were smokers, leaving 236 eligible patients. During the six month run in period 24 patients were withdrawn because of poor compliance and six moved away. After random allocation to one of the four study groups a further 19 patients were withdrawn because of poor compliance; a similar number of patients was withdrawn from each study group. Most of those withdrawn were in their teens or early $20 \mathrm{~s}$, and there were slightly more male than female patients ( 11 and eight respectively). A further seven patients were withdrawn because of insufficient symptoms, one moved away, and two in the group that received both the book and the tape did not have an opportunity to hear the tape. Of the 206 patients randomised into the four study groups, 177 completed the study $(86 \%)$. Eleven of these were not included in the analysis of knowledge of drugs because they were taking only prophylactic drugs and most of the questions referred to bronchodilators. The social class distribution of the 177 patients was: I, 18 patients (10\%); II, 42 (24\%); IIIa, 28 (16\%); IIIb, 67 (38\%); IV, $14(8 \%) ; \mathrm{V}, 4(2 \%)$; unemployed $4(2 \%)$. The proportion who dropped out was the same in all classes. The patients comprised 88 children (age $<13$ ), 26 teenagers, and 63 adults; there were 93 male and 84 female patients. The book had been given to 46 patients, the tape to 46 , both to 44 , and neither to 41 .

At the start of the study mean scores for knowledge of drugs varied (table I). Changes in these scores during the six month run in period resulted in all groups starting the intervention period with similar scores. Three months after the educational material had been distributed the mean change in scores for knowledge of drugs was significantly higher in the intervention groups $(p=0.002)$. Those patients who had received the tape, with or without the book, showed the greatest change. After a year the mean scores for knowledge of drugs in the control group had fallen to that found before the run in period. The group who received only the book maintained the improvement found after three months. Mean scores for knowledge of drugs decreased in both groups given the tape, but less in those who had also been given the book. The differences between the control and intervention groups remained significant $(p=0.007)$. There were no significant differences in the change in scores for knowledge of drugs among different ages (teenagers, adults, or parents answering for children) or between male and female patients. The change in these scores was somewhat less in the teenagers than the other groups but consistently lower in each study group.

Use of drugs after patients were supplied with books or tapes showed no significant difference among groups or when compared with use of drugs in the run in period. This was true both for the number of people taking different forms of treatment and for the quantities of drugs prescribed. There was no significant change among the groups in skill in the use of an inhaler or morbidity (as measured from the diary 
cards) after provision of the material. Rates of consultation for asthma and other problems were not significantly changed.

All 136 patients who were given the material used it. Of patients with the book, $60(67 \%)$ said that they understood it "very easily" and 28 (31\%) "fairly easily." For those with the tape the figures were 42 $(47 \%)$ and $46(51 \%)$ respectively. Although two thirds of those given only the tape did not know the nature of the contents of the accompanying card giving information on drugs, the remainder had used it. Seventy eight $(57 \%)$ of the patients given the material thought that their knowledge of asthma and its treatment was increased compared with $13(32 \%)$ of the control group $\left(\chi^{2}=6 \cdot 7, p<0.01\right)$. Among the 44 patients with both book and tape more attributed this increase to the book (24) than the tape (14).

Patients were asked for their general comments on the book and tape. The sections giving advice on drugs and coping with a bad attack were described as being most helpful in both the tape and book (table II). Some patients would have liked additional information: an explanation of the side effects of drugs, more details about steroids, advice on coping with asthma in young children, and a list of local self help groups.

Perception of disability fell in all of the groups who received the material but not in the control group (table III). The differences between groups were not significant. In the control group $24(59 \%)$ patients thought that they had made fewer visits to the doctor; 107 $(79 \%)$ of the patients in the groups given the educational material thought there was no change.

TABLE II-Number of patients receiving material who found information helpful

\begin{tabular}{|c|c|c|c|c|}
\hline \multirow[b]{2}{*}{$\begin{array}{l}\text { Type of information found } \\
\text { most helpful }\end{array}$} & \multicolumn{2}{|c|}{ Information in book } & \multicolumn{2}{|c|}{ Information on tape } \\
\hline & $\begin{array}{l}\text { Patients } \\
\text { given } \\
\text { book only }\end{array}$ & $\begin{array}{c}\text { Patients } \\
\text { given } \\
\text { book and tape }\end{array}$ & $\begin{array}{l}\text { Patients } \\
\text { given } \\
\text { tape only }\end{array}$ & $\begin{array}{c}\text { Patients } \\
\text { given } \\
\text { book and tape }\end{array}$ \\
\hline Advice on drugs & 11 & 9 & 12 & 4 \\
\hline Advice on coping with a bad attack & 4 & 4 & 2 & l \\
\hline Explanation of what asthma is & 3 & 5 & & 2 \\
\hline Reassuring presentation & 2 & 2 & 2 & 2 \\
\hline Discussion of causes, precipitating & & & & \\
\hline factors & 1 & 1 & 1 & \\
\hline Advice on allergies & & & 3 & 1 \\
\hline Advice on when to call the doctor & & & 2 & \\
\hline Question and answer section & & & 2 & 1 \\
\hline General advice & & 2 & & l \\
\hline Too much to itemise & 3 & 2 & 1 & 1 \\
\hline
\end{tabular}

TABLE III-Change in perception of disability between end of run in period and one year after intervention

\begin{tabular}{lccc}
\hline Study group & $\begin{array}{c}\text { No (\%) perceiving } \\
\text { disability as less }\end{array}$ & $\begin{array}{c}\text { No(\%) perceiving } \\
\text { no change }\end{array}$ & $\begin{array}{c}\text { No(\%) perceiving } \\
\text { disability as greater }\end{array}$ \\
\hline Control $(\mathrm{n}=41)$ & $15(37)$ & $10(24)$ & $16(39)$ \\
Book $(\mathrm{n}=46)$ & $26(57)$ & $6(13)$ & $14(30)$ \\
Tape $(\mathrm{n}=46)$ & $29(63)$ & $4(9)$ & $13(28)$ \\
Book and tape $(\mathrm{n}=44)$ & $29(66)$ & $4(9)$ & $11(25)$ \\
\hline
\end{tabular}

\section{Discussion}

We showed that a specially prepared book or tape in conjunction with a diary card on which to note morbidity, can increase knowledge of use of drugs without any effort from the doctor apart from giving the material to patients. Encouragement to use the material and willingness to discuss its contents might enhance this effect.

Self management is an important ingredient of good care of asthma. To cope with asthma the patient needs to understand the drugs taken' and the mechanisms of the disease, recognise and anticipate changes, and be able to adjust treatment accordingly. A prerequisite for improving self management is increased knowledge. Ways of increasing such knowledge have been studied for various diseases, but few principles have emerged. A review of 320 accounts of education of patients with chronic disease concluded that efforts to improve knowledge were rarely successful unless allied to behavioural or environmental changes. ${ }^{10}$ Such methods have been used successfully in the United Kingdom. For instance, diabetic patients whose illness was poorly controlled were shown a video film and given demonstrations; they had more knowledge, better compliance, and lower concentrations of haemoglobin $\mathrm{A}_{1}$ than similar patients given only a diet sheet or a diet sheet and demonstrations."

Programmes for improving care of patients with asthma in general practice in the United Kingdom have been evaluated. Modell et al used management plans that included educating patients with asthma in a group practice. They found that peak flow rates were increased and severity of asthma was reduced, but interpretation of their data is difficult because of the lack of controls. They suggested that more use could be made of booklets and handouts. Hilton et al compared patients given maximum and limited programmes of education with a control group and found no significant differences in self management, morbidity (assessed by questionnaire), or knowledge of drug actions, but the group who received maximum education had significantly improved knowledge of the mechanisms of asthma and tended to attend general practitioners instead of the casualty department.' A book and audiocassette were used as part of the package. The effects of the book and tape were not compared, but $31 \%$ of the patients found the book useful and $67 \%$ found the tape very useful. Both of these studies were time consuming for the general practitioners taking part; thus one of our objectives was for the material to stand alone and not require any action other than handing it out. This would make it acceptable for routine use in general practice, where time is sometimes at a premium. We were strongly influenced by previous studies of a reference manual for management of minor illnesses. ${ }^{78}$

The increase in knowledge of the use of drugs that occurred in the intervention groups was modest but significant. The questions were pertinent to everyday management of asthma and covered topics about which patients are often mistaken, including the absence of addiction or tachyphylaxis with drugs for asthma, the need to use a bronchodilator early in episodes of wheezing, the need to take prophylactic drugs regularly, the superiority of inhaled drugs, and the use of bronchodilators before exercising. The absence of significant improvement in knowledge of asthma and drugs during the run in period and in the control group suggests that merely keeping the diary card was not responsible for the increased knowledge.

The reduction in perception of disability that occurred in the groups given educational material may have been due to the increased confidence resulting from the concern shown to the patients and the observations made (the Hawthorne effect). ${ }^{12}$ If this were so, however, it must have been the material rather than keeping the diary card, which all groups did, that prompted this. Hilton et al found that increased confidence was a common response in their study, ${ }^{5}$ but it is not clear whether this increased confidence is good or bad.

The lack of objective change in morbidity as measured by diary cards possibly reflects the insensitivity of the method of recording such data. Morbidity varies among patients with asthma, and a diary card tailored to each patient might have detected more subtle changes. Anecdotal evidence from the final interviews suggested that trouble from asthma was reduced in many patients as a result of something they had learnt from the material-for example, four 
patients learnt about inhaling bronchodilators before starting exercise and found this beneficial.

The lack of measurable change in use of drugs, skill in using an inhaler, and morbidity as measured by diary cards may also have been affected by the fact that the patients were from practices eager to participate in this study. Possibly these practices already managed their asthmatic patients well so that further improvement was difficult; patients from average practices might benefit more.

Comprehension of the materials, based on subjective estimates, was satisfactory. Information about drugs was judged the most valuable, even though two thirds of patients who had been given the tape were unaware of the card summarising the information on drugs. Both book and tape seemed to function well as reference material for the one third of patients who used them in this way, although patients given both materials used the book more often. There was no evidence that the group given only the tape used the reference material less than the group given only the book, so the bother of playing the tape did not seem to be a deterrent. Some patients found the tape more convenient because they could play it in the car or while doing the washing up. With regard to subjective acquisition of knowledge, twice as many patients in the groups given the book or tape, or both, than the control group thought that they had learnt something.

The differences in perceived frequency of visits to the doctor are curious: only the control group thought that there had been a change, and that they saw the doctor less often. This might be because they thought that they would be expected to see the doctor less, whereas the book and tape encouraged patients to see their doctor about any problems they might have.

The overall preference for the book is paradoxical in view of the greater knowledge about use of drugs of the patients given the tape. These findings may have arisen because a tape has to be heard through and unsought information listened to (and perhaps remembered) while unsought material in a book can be ignored. An audiocassette may therefore be better at putting across what patients need to know but may not recognise as important while a book may be better at providing information that patients actually want. Keeping diary cards may also be important, and a suitably designed combination of book, tape, and diary card might be best of all.

We thank Professor J M Elwood, Dr M J Sheldon, and Dr A J Hedley for their support and help; Mr Alan Wright for ensuring the quality of the books and tapes; Dr Louis Phillips for his help with the birth of the project; and Jeremy Laurance for writing the information book. We also thank the general practitioners who allowed us to study their patients, Joan Jenkinson for her clerical work, and especially the patients themselves. The project was financially supported by Allen and Hanburys Ltd.

1 Fireman P, Friday GA, Gira C, Vierthaler WA, Michaels L. Teaching selfmanagement skills to asthmatic children and their parents in an ambulatory care setting Pediatrics 1981;68:341-8.

2 Maiman AL, Green LW, Gibson G, MacKenzie EJ. Education for selftreatment by adult asthmatics. FAMA 1979:241:1919-22.

3 Lewis EC, Rachelefsky G Lewis MA, de la Sota A Kaplan MA Randomized trial of ACT (asthma care training) for kids. Pediatrics 1984;74:478-86.

4 Modell M, Harding JM, Horder EJ, Williams PR. Improving the care of asthmatic patients in general practice. $\mathrm{Br}$ Med $\mathcal{F}$ 1983;286:2027-30.

5 Hilton S, Sibbald B, Anderson HR, Freeling P. Controlled evaluation of the effects of patient education on asthma morbidity in general practice. Lancet $1986 ; \mathrm{i}: 26-9$.

6 Ley P, Jain VK, Skilbeck CE. A method for decreasing patients' medication errors. Psychol Med 1976;6:599-601.

7 Morrell DC, Avery AJ, Watkins CJ. Management of minor illness. Br Med $\mathcal{f}$ $1980 ; 280: 769-71$

8 Anderson JE, Morrell DC, Avery AJ, Watkins CJ. Evaluation of a patien education manual. BrMed f 1980;281:924-6.

Harding JM Modell M. How patients manage asthma $f R$ Coll Gen Pract 1985;35:226-8.

10 Mazzuka SA Does patient education in chronic disease have therapeutic value? f Chronic Dis 1982;35:521-9.

11 McCulloch DK, Mitchell RD, Ambler J, Tattersall RB. Influence of imaginative teaching of diet on compliance and metabolic control in insulin dependent diabetes. BrMed $\mathcal{F}$ 1983;287:1858-61.

12 Blum ML, Naylor JC. Industrial psychology: theoretical and social foundations. New York: Harper and Row, 1968:306-27.

(Accepted 23 February 1988)

\section{ONE HUNDRED YEARS AGO}

Sir Michael Hicks-Beach's answer to Dr. Tanner's question with regard to the hospital accommodation supplied in transoceanic passenger ships was one of those cut and dried statements which permanent officials put into the mouths of their parliamentary spokesmen when inconvenient topics are raised. "The departmental officers whose business it is to see to these matters have made no complaints, and everything is for the best in the best possible world." A comfortable doctrine for the official mind! Woe betide, therefore, the officer who dares to complain. The President of the Board of Trade, with more ingenuity than ingenuousness, tried to shift the blame on to the ships surgeons; it was their duty to see that the requirements of the law are not evaded; if these have been evaded, then the surgeons who have not reported the evasions have failed in their duty; and Sir Michael Hicks-Beach cannot pursue the inquiry further, because he would not like to publish anything to the disadvantage of the surgeons. Such delicate consideration is quite touching, but people of a less delicate fibre may be disposed to ask the President to ascertain what has been the fate of surgeons who have found fault; for though the Board of Trade has not heard of it, fault has been found, as might be ascertained on application to the Local Government Board. Are any of these courageous surgeons afloat now? Is it not well known that much less than a formal complaint, even a protest, or a suspicion that the surgeon once, for an imprudent moment, thought of making a protest, is enough to lead to instant dismissal? Are not the agreements between the steamboat companies and the surgeons so drawn that these officers are at the mercy of the companies, who may even refuse, without reasonable cause given, to pay a salary fairly earned? We would suggest to Sir Michael Hicks-Beach that it is his duty to find the answer to these questions; they have already been answered in these columns, but the official mind loves an official answer.
When the Public Health service of this country comes to be reformed on a sound basis, it will be necessary to make the Health Department responsible for the supervision of the health of the passengers carried by emigrant and other transoceanic passenger ships; then the responsibility would be met, now it is shirked because it falls upon a Board which has no sanitary advisers. The Board of Trade does not understand the gravity of the case or the importance of its duties in this matter, and in consequence very serious inconvenience and expense are inflicted upon our Colonies and upon the United States. Why do the emigrants not complain? asks Sir Michael Hicks-Beach. O sancta simplicitas! How in the name of common sense, which after all has more to do with practical affairs, is an emigrant newly landed in a strange country to make his grievances known to the British Board of Trade? Why should he trouble his head about it? The worst is over, he has escaped from the dominion of red tape, and his thoughts are all in the future. Obviously the ship ought to carry some independent officer responsible not to the ship owners, whose interest it is to smother complaints, but to the department whose business it is to investigate them. Such an officer the ship's surgeon might be, and where the plan has been tried, as in the emigration services of the Australasian Colonies, he has well discharged his duties. It is all very well for the official person to give official answers, and shelve the difficulty, but sooner or later the United States and our Colonies will grow tired of waiting, and the Board will have to take down the tape-bound parcel of papers from its shelf, and find, under external compulsion, a solution to a difficulty which might now be made to cease to exist by the simple expedient of doing what is just and right because it is right and just.

(British Medical Fournal 1888;ii:85.) 